\title{
EFFECTS OF GENDER AND PARENTING STYLES ON PROMISCUOUS BEHAVIOUR AMONG ADOLESCENTS WITH HEARING IMPAIRMENT IN SECONDARY SCHOOLS IN IBADAN, OYO STATE, NIGERIA
}

\author{
Onyezere, Joyce Ifeoma ${ }^{1}$, \\ Onyezere, John Osondu ${ }^{2 i}$ \\ ${ }^{1} \mathrm{PhD}$, Department of Special Education, \\ Faculty of Education, \\ University of Ibadan, Ibadan, \\ Nigeria \\ ${ }^{2} \mathrm{PhD}$, Department of Human Kinetics \\ and Health Education, \\ University of Port Harcourt, Rivers State,
}

Nigeria

\begin{abstract}
:
Adolescents with hearing impairment have sexual and reproductive health needs like their normal counterparts. However, reports have shown that many adolescents with hearing impairment in Ibadan often engage in promiscuous behaviour which is inimical to their health. Previous studies focused on factors predisposing adolescents with hearing impairment to promiscuous behaviour with little consideration to curb this behaviour.

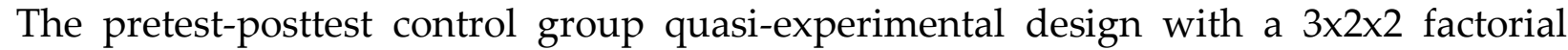
matrix was adopted. Purposive sampling technique was used to select the three integrated secondary schools. Seventy-two (43 males and 29 females) Senior Secondary School I and II adolescents with hearing impairment were selected using purposive sampling technique. The school health record was used to screen the participants. Participants were randomly assigned to Sexuality education training (49), Assertiveness skill training (14) and the control (9) groups. The instruments used for data collection were Adolescent Sexual Behaviour Inventory, Sexual Assertiveness Scale and Promiscuous Behaviour Scale. Data was analyzed using Analysis of Covariance (ANCOVA) at .05 level of significance. The results showed that gender had a significant main effect on promiscuous behaviour among adolescents with hearing impairment ( $\mathrm{F}$ $(1.70)=8.27$, partial $\eta^{2}=0.12$ ), while Parenting style had a significant main effect on promiscuous behaviour of adolescents with hearing impairment $\left(F_{(1,70)}=4.25\right.$, partial $\eta^{2}=0.07$ ). the result also showed that there was no significant difference between parenting styles and gender in relation to promiscuous behaviour of Adolescents with
\end{abstract}

i Correspondence: email joyceify2003@yahoo.co.uk, john.onyezere@uniport.edu.ng 
hearing impairment. Sexuality education and assertiveness skill training were effective in reducing promiscuous behaviour among adolescents with hearing impairment in secondary schools in Ibadan, Oyo State. Teachers, special educators, guidance counselors and other stakeholders should adopt both strategies for reduction of promiscuous behaviour among adolescents with hearing impairment.

Keywords: sexuality education, assertiveness skills, parenting styles, gender, promiscuous behaviour

\section{Introduction}

The period of adolescence is a unique stage in every person's life, and it is a period of transition from childhood to adulthood. Many adolescents manage this transformation successfully while others experience major stress and find themselves engaging in behaviours (such as sexual experimentation, exploration and promiscuity) that place their well-being at risk. Adolescence has been described as a stage among human beings where a lot of physiological as well as anatomical changes take place resulting in reproductive maturity in the adolescents (Kirby, 2006). Adolescents, especially those with hearing impairment, display promiscuous behaviours and developmental characteristics that place them at risk for sexually transmitted infections and other related sexual problems (Kaplan, 2004).

In most African countries, Nigeria in particular, matters relating to sex and sexuality are usually shrouded in secrecy (Esere, 2006). The adolescents have no free access to the information they need on sexuality, while questions bordering on sexuality and girl-boy relationships are usually hushed up and regarded as taboos. From the above assertion, it implies that if this aspect of the adolescents' life is not adequately managed, the outcome would be the exhibition of sexual behavioural patterns that are capable of producing such reproductive health problems as unwanted pregnancy, abortions, sexually transmitted infections, gynecological problems, abandoned babies and single parenthood with all its attendant problems.

Adolescents with hearing impairment in Nigeria are some of the most disadvantaged individuals in society and their sexual and reproductive health (SRH) have long been neglected (United Nations Population Fund Report, 2007). In line with the above assertion, adolescents with hearing impairment often find it difficult to disseminate sex information given to them. This also places a burden on them in terms of acquisition of information related to sexuality and the attendant consequences of promiscuous behaviour. The danger inherent in this development is that the uninformed adolescents with hearing impairment may continue to engage in unprotected sexual adventures thereby spreading sexually transmitted infections.

Adolescents can be said to be promiscuous when they have two or more sex partners at the same time, and have sexual intercourse with all of them. Reports from several parts of Nigeria indicate that there is a high level of promiscuity among young 
people especially adolescents with hearing impairment (Okpani and Okpani, 2000; Oladepo and Brieger, 2000; Izugbara, 2001). The combination of social discrimination against these people and the precariousness of essential social and health services, however, means that adolescents with hearing impairment are often more vulnerable to Sexual and Reproductive Health (SRH) problems such as unplanned pregnancies, sexually transmitted infections (STIs) and sexual abuse, than others.

Considerable research (Kheswa and Takatshana, 2014; Baldasare, 2012) has demonstrated that male and female differ somewhat in attitudinal, physiological, and behavioural aspects of sexuality. Attitudes, behaviours, sensations, drives, emotions, and cognitions all constitute the experience of sexual intercourse. Yet, there has been a paucity of research addressing the issue of gender differences in the promiscuous behaviour of adolescents with hearing impairment.

Parenting style has been playing very crucial roles in adolescents' transition to adulthood. Parenting has been recognized as a major vehicle in socializing the child; Parenting, according to Okpako (2004) is the act of parenthood, the child upbringing, training and rearing or child education. Parenting style is the nature of control parents' exercise over their children and those identified include authoritarian, permissive and democratic styles. The researcher limited herself to two of these styles, that is, authoritarian and permissive parenting styles. The justification for this choice stems from the fact that the two parenting styles are the mostly used in our contemporary society.

It is based on this premise therefore that this research focused on effects of gender and parenting styles on promiscuous behaviour among adolescents with hearing impairment in secondary schools in Ibadan, Oyo State.

\section{Statement of the Problem}

Early sexual debut is known to increase the risks of teenage pregnancy, maternal and perinatal mortality, and sexually transmitted infections (STIs), including HIV. Major prevention campaigns have identified promiscuous behaviour as one of the major risky behaviours among adolescents. Moreover, with the changes that have occurred in relation to societal norms regarding the practice of sex before marriage and easier access to effective modern methods of contraception, more adolescents are engaging in indiscriminate sexual exploits and experimentation. Consequently, they are having several partners. Adolescents with hearing impairment are at higher risk of experiencing unintended premarital pregnancy and both young girls and young boys are at higher risk of contracting sexually transmitted infections (STI), including the human immunodeficiency virus (HIV). The parenting styles used by parents in the upbringing of their children especially adolescents with hearing impairment plays a very significant role in the future conduct of their children in relation to promiscuous behaviour. It is based on this premise therefore that this research focused on effects of gender and parenting styles on promiscuous behaviour among adolescents with hearing impairment in secondary schools in Ibadan, Oyo State. 


\subsection{Hypotheses}

The following research hypotheses were formulated and tested at .05 level of significance:

1) There is no significant interaction effect of treatment and gender on promiscuous behaviour of adolescents with hearing impairment.

2) There is no significant interaction effect of treatment and parenting style on promiscuous behaviour of adolescents with hearing impairment.

3) There is no significant interaction effect of parenting style and gender on promiscuous behaviour of adolescents with hearing impairment.

\section{Methodology}

The research design adopted for this study was the pretest-posttest control group quasi-

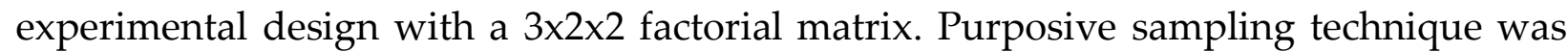
used to select the three integrated secondary schools in Ibadan, Oyo State. Seventy-two (43 males and 29 females) Senior Secondary School I and II adolescents with hearing impairment were selected using purposive sampling technique. The school health record was used to screen the participants. Participants were randomly assigned to Sexuality education training (49), Assertiveness skill training (14) and the control (9) groups. Treatment lasted eight weeks. Instruments used were Adolescent Sexual Behaviour Inventory (by Falaye 1998) made up of four sections, namely Pubertal changes and reproductive biology $(\alpha=0.75)$, Source of adolescents' sexual information $(\alpha=0.73)$, Adolescents' sexual activities and experiences $(\alpha=0.68)$, Adolescents' sexual values and perception of reproductive health matters $(\alpha=0.94)$, Sexual assertiveness $(\alpha=0.82)$ and Promiscuous Behaviour $(\alpha=0.78)$ scales. Data were analysed using Analysis of covariance and Scheffe post- hoc test at 0.05 level of significance.

\section{Results and Discussion of Findings}

Table 1: Summary of Analysis of Covariance (ANCOVA) of Pre-Post Test Interactive Effect of Promiscuous Behaviour of Adolescents with Hearing Impairment in the Treatment Groups, Gender and Parenting Styles

\begin{tabular}{|l|c|c|c|c|c|c|}
\hline Source & $\begin{array}{c}\text { Sum of } \\
\text { Squares }\end{array}$ & $\mathbf{d f}$ & $\begin{array}{c}\text { Mean } \\
\text { Square }\end{array}$ & $\mathbf{F}$ & Sig. & $\begin{array}{c}\text { Eta } \\
\text { Squared }\end{array}$ \\
\hline Corrected Model & $989.152^{\mathrm{a}}$ & 11 & 89.923 & 5.618 & .000 & .507 \\
Intercept & 527.700 & 1 & 527.700 & 32.969 & .000 & .355 \\
Covariance & 17.832 & 1 & 17.832 & 1.114 & .295 & .018 \\
\hline One-way interaction & & & & & & \\
Treatment & 100.883 & 2 & 50.442 & 3.151 & .05 & .095 \\
Gender & 132.372 & 1 & 132.372 & 8.270 & .006 & .121 \\
Parenting Style & 68.091 & 1 & 68.091 & 4.254 & .043 & .066 \\
\hline Two-way interaction & & & & & & \\
Treatment x Gender & 56.023 & 2 & 28.012 & 1.750 & .183 & .055 \\
Treatment x Parent style & 53.774 & 2 & 26.887 & 1.680 & .195 & .053 \\
Gender x Parenting style & 11.203 & 1 & 11.203 & .700 & .406 & .012 \\
\hline
\end{tabular}



WITH HEARING IMPAIRMENT IN SECONDARY SCHOOLSIN IBADAN, OYO STATE, NIGERIA

\begin{tabular}{|l|c|c|c|c|c|c|}
\hline \hline Three-way interaction & .216 & 1 & .216 & .014 & .908 & .000 \\
Treatment x Gender $x$ & & & & & \\
Parenting Style & 960.348 & 60 & 16.006 & & & \\
\hline Error & 27262.000 & 72 & & & & \\
Total & 1949.500 & 71 & & & & \\
Corrected Total & & \\
\hline
\end{tabular}

a. $\quad$ R Squared $=.507$ (Adjusted R Squared $=.417$ )

Hypothesis 1: There is no significant interaction effect of treatment and gender on promiscuous behaviour of adolescents with hearing impairment.

The result in Table 1 showed that there was no significant interaction effect of treatment (Sexuality Education Programme and Assertiveness Skill Training) and gender (Male and Female) in the pretest-posttest promiscuous behaviour scores of adolescents with hearing impairment in the experimental groups $\left(\mathrm{F}_{(2,69)}=1.750, \mathrm{p}>.05 ; \eta^{2}=.055\right)$. This implies that the effect of the interaction of treatment and gender on promiscuous behaviour of adolescents with hearing impairment was not statistically significant and it showed that treatment is not dependent on gender. Therefore, the null hypothesis is accepted.

The mean and standard deviation scores of participants based on treatment and gender are presented in Table 2 below:

Table 2: Mean Score and Standard Deviation of Treatment and Gender

\begin{tabular}{|l|l|c|c|c|}
\hline Treatment Groups & Gender & Mean & Std. Deviation & N \\
\hline Sexuality Education Programme & Male & 20.7500 & 5.2915 & 32 \\
& Female & 15.0000 & 2.9368 & 17 \\
& Total & 18.7551 & 5.3484 & 49 \\
\hline Assertiveness Skill Training & Male & 22.1000 & 3.7845 & 10 \\
& Female & 21.0000 & 2.9439 & 4 \\
& Total & 21.7857 & 3.4092 & 14 \\
\hline Control & Male & 22.0000 & & 1 \\
& Female & 13.0000 & 1.4142 & 8 \\
& Total & 14.0000 & 2.4495 & 9 \\
\hline Total & Male & 17.0930 & 3.7341 & 43 \\
& Female & 15.1724 & 3.8644 & 29 \\
& Total & 16.3194 & 3.8778 & 72 \\
\hline
\end{tabular}

Table 2 shows that the mean scores of the experimental groups and the control group in relation to gender are revealed thus: Sexuality Education Programme $(\bar{x}=18.75)$, Assertiveness Skill Training $(\bar{x}=21.78)$ and Control $(\bar{x}=14.00)$. This implies that there was no significant interaction effect between treatments and gender on promiscuous behaviour of adolescents with hearing impairment.

The second hypothesis stated that there is no significant main effect of gender on promiscuous behaviour of adolescents with hearing impairment. The finding from the Analysis of Covariance in Table 1 indicated that there was significant main effect of gender in the post test scores on promiscuous behaviour of adolescents with hearing 
impairment in the experimental and control groups. Therefore, the null hypothesis is not accepted. This reveals significant differences did exist between male and female adolescents with hearing impairment with respect to promiscuous behaviour as the mean score of the male adolescents with hearing impairment (21.09) was significantly different from that of their female counterpart (15.08) as shown in Table 2.

This implies that gender has significant main effect on promiscuous behaviour of adolescents with hearing impairment. Gender did influence the promiscuous behaviour scores of the participants.

This finding is in line with that of Faílde and Teva (2009) and Lindberg (2000), who found that, in general, males tend to have more sexual partners than females, and they also tend to use condoms less frequently than women during vaginal intercourse. Also, Rotermann and McKay (2009), suggests that men are likely to have a higher number of sex partners than women but that the difference between men and women in this regard is considered in the small to medium range. In a study conducted by Okafor and Obi (2005) among adolescents in Enugu, Nigeria indicated that the prevalence of sexual activity was $76.8 \%$ with $85.4 \%$ of females and $62.3 \%$ of the males having more than one sexual partner

Hypothesis 2: There is no significant interaction effect of treatment and parenting style on promiscuous behaviour of adolescents with hearing impairment.

The result in Table 1 shows that there is no significant interaction effect between treatments (Sexuality Education Programme and Assertiveness Skill Training) and parenting styles (Authoritarian and Permissive) in the pre-post test scores on promiscuous behaviour of adolescents with hearing impairment in the experimental and control groups $\left(F_{(2,69)}=1.680, p>.05 ; \eta^{2}=.053\right)$. This implies that the interaction effect of treatment and parenting styles on promiscuous behaviour of adolescents with hearing impairment was not statistically significant and it showed that treatment is not dependent on parenting styles. Therefore, the null hypothesis is hereby accepted.

The mean scores and standard deviation of participants based on treatment and parenting styles are presented in Table 3 below:

Table 3: Mean Score and Standard Deviation of Treatment and Parenting Styles

\begin{tabular}{|l|l|c|c|c|}
\hline Treatment Groups & Parenting Style & Mean & Std. Deviation & $\mathbf{N}$ \\
\hline Sexuality Education Programme & Authoritarian & 21.7826 & 4.9631 & 23 \\
& Permissive & 16.0769 & 4.1658 & 26 \\
& Total & 18.7551 & 5.3484 & 49 \\
\hline Assertiveness Skill Training & Authoritarian & 23.8333 & 3.5449 & 6 \\
& Permissive & 20.2500 & 2.7124 & 8 \\
& Total & 21.7857 & 3.4902 & 14 \\
\hline Control & Authoritarian & 15.3333 & 6.1101 & 3 \\
& Permissive & 13.3333 & .8165 & 6 \\
& Total & 14.0000 & 3.2787 & 9 \\
& & & & \\
\hline Total & Authoritarian & 21.5625 & 5.1678 & 32 \\
& Permissive & 16.5000 & 4.1324 & 40 \\
& Total & 18.7500 & 5.2400 & 72 \\
\hline
\end{tabular}


Table 3 shows that the mean scores of the experimental groups (treatments) and the control group in relation to parenting styles are revealed thus: Sexuality Education Programme $(\bar{x}=18.75)$, Assertiveness Skill Training $(\bar{x}=21.78)$ and Control $(\bar{x}=14.00)$. This implies that there was no significant interaction effect between treatments and parenting styles on promiscuous behaviour of adolescents with hearing impairment.

The finding from the Analysis of Covariance in Table 1 indicated that there was significant main effect of parenting styles in the post test scores on promiscuous behaviour of adolescents with hearing impairment. Therefore, the null hypothesis is not accepted. This shows that statistical differences did exist between the authoritarian and permissive styles of parenting of adolescents with hearing impairment on promiscuous behaviour. It suggests that parenting styles whether authoritarian or permissive differ significantly on promiscuous behaviour of adolescents with hearing impairment. It also showed that parenting styles did influence the promiscuous behaviour scores of participants.

The finding negates that of Ang and Goh (2006) whose report showed that authoritarian parenting styles has negative connotation in literature because of the negative behaviour outcomes of adolescents and children. However, on the same note outcome of some researches revealed that authoritarian parenting yielded positive effects on Asian and Indian adolescents (Ang and Goh, 2006). They also found that authoritative parenting style has more positive effects on the adolescent promiscuous behaviour than permissive parenting styles. Also, authoritarian parenting is characterized by harsh disciplinary attitudes and rigid boundaries. Authoritarian parents demand obeisance, discourage open communication and exert high level of restrictive psychological control that is more adult-centred than child-centred.

Hypothesis 3: There is no significant interaction effect of parenting style and gender on promiscuous behaviour of adolescents with hearing impairment.

The result in Table 1 shows that there is no significant interaction effect between parenting styles and gender in the pre-post test scores on promiscuous behaviour of adolescents with hearing impairment in the experimental and control group $\left(\mathrm{F}_{(1,70)}=.700\right.$, $\left.\mathrm{p}>.05 ; \eta^{2}=.012\right)$. This implies that the interaction effect between parenting styles and gender in relation to promiscuous behaviour of adolescents with hearing impairment was not statistically significant and it showed that treatments had no impact on parenting styles and gender. Therefore, the null hypothesis is accepted.

The mean scores and standard deviation of participants based on parenting styles and gender are presented in Table 4 below:

Table 4: Mean Score and Standard Deviation of Parenting Styles and Gender

\begin{tabular}{|l|l|c|c|c|}
\hline Gender & Parenting Style & Mean & Std. Deviation & N \\
\hline Male & Authoritarian & 22.2692 & 4.8130 & 26 \\
& Permissive & 19.2941 & 4.6201 & 17 \\
& Total & 21.0930 & 4.9078 & 43 \\
\hline \multirow{2}{*}{ Female } & Authoritarian & 18.5000 & 5.9917 & 6 \\
& Permissive & 14.4348 & 2.0632 & 23 \\
\hline
\end{tabular}



WITH HEARING IMPAIRMENT IN SECONDARY SCHOOLSIN IBADAN, OYO STATE, NIGERIA

\begin{tabular}{|l|l|l|l|l|}
\hline \hline & Total & 15.2759 & 3.5446 & 29 \\
\hline Total & Authoritarian & 21.5625 & 5.1678 & 32 \\
& Permissive & 16.5000 & 4.1324 & 40 \\
& Total & 18.7500 & 5.2400 & 72 \\
\hline
\end{tabular}

Table 4 shows the mean scores of parenting styles with gender as: Male $(\bar{x}=21.09)$ and Female $(\bar{x}=15.27)$. This implies that there was no significant interaction between parenting styles and gender on promiscuous behaviour of adolescents with hearing impairment.

There is no significant interaction effect of parenting style and gender on promiscuous behaviour of adolescents with hearing impairment. The finding from the Analysis of Covariance in Table 1 indicated that there is no significant interaction effect between parenting styles and gender in the post test scores on promiscuous behaviour of adolescents with hearing impairment. Therefore, the null hypothesis is accepted. The finding is in line with that of Lloyd (2010) who stated that parenting styles and gender had no moderating influence on promiscuous behaviour scores of adolescents with hearing impairment. Whether an adolescent with hearing impairment is male or female, brought up through authoritarian or permissive parenting styles, there is no difference in the way he/she expresses himself/herself in relation to promiscuous behaviour. Hence, parenting styles and gender had no interactive effect on promiscuous behaviour of adolescents with hearing impairment.

\section{Conclusion}

Based on the findings of the study, the following conclusions were made that:

1. there was significant main effect of gender in the post test scores on promiscuous behaviour of adolescents with hearing impairment in the experimental and control groups. This reveals significant differences did exist between male and female adolescents with hearing impairment with respect to promiscuous behaviour as the mean score of the male adolescents with hearing impairment (21.09) was significantly different from that of their female counterpart (15.08)

2. there is no significant interaction effect between treatments (Sexuality Education Programme and Assertiveness Skill Training) and parenting styles (Authoritarian and Permissive) in the pre-post test scores on promiscuous behaviour of adolescents with hearing impairment in the experimental and control groups.

3. there is no significant interaction effect between parenting styles and gender in the pre-post test scores on promiscuous behaviour of adolescents with hearing impairment in the experimental and control group. This implies that the interaction effect between parenting styles and gender in relation to promiscuous behaviour of adolescents with hearing impairment was not statistically significant and it showed that treatments had no impact on parenting styles and gender. 


\subsection{Recommendations}

The following recommendations were made based on the findings of the study:

1. There is the need to recommend the two treatment modes (sexuality education programme and assertiveness skill training) used in this study to schools for adolescents with hearing impairment.

2. Parents has a very big role to play in helping the adolescents with hearing impairment to function effectively in school and the society at large through their styles of parenting.

3. Adequate attention should be given to both gender (male and female) when it comes to using sexuality education and assertiveness training in reducing promiscuous behaviour of adolescents with hearing impairment.

\section{Conflict of Interest Statement}

The authors declare no conflicts of interests.

\section{About the Authors}

Onyezere, Joyce Ifeoma (PhD) is a Sign Language Interpreter in Special Education, Faculty of Education, University of Ibadan, Ibadan, Nigeria. Educational Qualifications: $\mathrm{PhD}$ in Special Education (2017). M.Ed. in Special Education (2004), B.Ed. in Special Education/Political Science (1999), N.C.E. in Special Education/Social Studies (1995). Area of Research Interest: Dr. Onyezere, Joyce Ifeoma's research interest is in the area of Hearing Impairment in Special Education. She makes use of sign language in communicating with the hearing-impaired individuals. She has also researched in the area of Health Education as it affects the hearing-impaired population.

Onyezere, John Osondu (PhD) is Senior Lecturer in Health Education, Educational Qualifications PhD in Health Education (2009), M.Ed. in Health Education (1997), B.Ed. in Physical and Health Education (Second Class Upper Division) (1992). Dr. Onyezere, John Osondu's research interest is in Health Education. He has carried out research in School Health Education, Community Health Education, Safety Education and also has experience in Health Education Programme Development and Implementation.

\section{References}

Ang, R. P. and Goh, D. H. (2006). Authoritarian parenting Style in Asian Societies: A Cluster - analytic Investigation. Contemporary Family Therapy: An international Journal. 28 (1): 132 - 151.

Baldasare, A. (2012). Gender-Based violence: Focus on Africa. SAI-from vision to results

Esere, M. O. (2006). Effect of sex education programme on at-risk sexual behaviours of school-going adolescents in Ilorin, Nigeria. Nigerian Journal of Guidance and Counselling, 11,1:34-42. 
Izugbara, C. O. (2001). Tasting the forbidden fruit. The social context of debut sexual encounters among young persons in a rural Nigerian community. Afr. Journal of Reproductive Health, 5(2): 22 - 29.

Kaplan, P. S. (2004). Adolescence. Boston: Houghton Mifflin Company

Kheswa, J. G. and Takatshana, S. (2014). Exploring the impact of abortion among female students at South Africa University campus: A Phenomenological Study. Academic Journal of Interdisciplinary Studies, 3(1): 111-120.

Kirby, D., A. Obasi and B. Laris (2006). The Effectiveness of Sex Education and HIV Interventions in Schools in Developing Countries, Preventing HIV/AIDS in Young People: A Systemic Review of the Evidence from Developing Countries. Geneva: World Health Organization.

Lindberg, L. D. (2000). Multiple threats: the co-ocurrence of teen health risk behaviors. In: Department of Health and Human Services (DHHS), editor. Trends in the wellbeing of America's children and youth, 1999. Washington DC: DHHS; 2000.

Lloyd, C. B. (2010). The role of schools in promoting sexual and reproductive health among adolescents in developing countries. in: S. Malarcher (Ed.) Social determinants of sexual and reproductive health Informing future research and programme implementation. World Health Organization, Geneva.

Okafor, I. I. and Obi, S. N. (2005). Sexual risk behaviour among undergraduate students in Enugu, Nigeria. Journal of Obstetrics and Gynecology, 25(6): 592-595

Okpako, J. E. F. (2004). Parenting the Nigerian Adolescents Towards Smooth Transition to Adulthood. In Contemporary Issue and Research in Adolescents (I. A. Nwazuoke; O. Bamgbose \& O. A. Morokola (Ed) Ibadan Omoade Printing Press. pp 275 - 288.

Okpani, A. O. U. and Okpani, J. U. (2000). Sexual activity and contraceptive use among female adolescents: a report from Port Harcourt, Nigeria. Afr. Journal of Reproductive Health, 4(1): 40-47.

Oladepo, O. and Brieger, W. R. (2000). Sexual attitudes and behavior of male secondary school students in rural and urban areas of Oyo State, Nigeria. Afr. Journal of Reproductive Health, 4(2): $21-34$.

Rotermann, M. and McKay, A. (2009). Condom use at last sexual intercourse among unmarried, not living common-law 20 - to 34-year-old Canadian young adults. The Canadian Journal of Human Sexuality, 18 (3): 75-88.

United Nation Population Fund (2007). Emerging Issues: Sexual and Reproductive Health of Person with disabilities. UNFPA. 

be applied to their work. Under the terms of this license, no permission is required from the author(s) or publisher for members of the community to copy, distribute, transmit or adapt the article content, providing a proper, prominent and unambiguous attribution to the authors in a manner that makes clear that the materials are being reused under permission of a Creative Commons License. Views, opinions and conclusions expressed in this research article are views, opinions and conclusions of the author(s). Open Access Publishing Group and European Journal of Special Education Research shal not be responsible or answerable for any loss, damage or liability caused in relation to/arising out of conflict of interests, copyright violations and inappropriate or inaccurate use of any kind content related or integrated on the research work. All the published works are meeting the Open Access Publishing requirements and can be freely accessed, shared, modified, distributed and used in educational, commercial and non-commercial purposes under a Creative Commons Attribution 4.0 International License (CC BY 4.0). 